\title{
Influência da monofenilbutazona associada ou não ao omeprazol sobre o sistema digestório e renal de pôneis hígidos
}

\author{
Influence of mofebutazone associated or not to omeprazole on the digestive and renal tracts of \\ healthy ponies
}

\author{
José de Oliveira Pinto ${ }^{\mathrm{I}}$ Maria Verônica de Souza ${ }^{\mathrm{I}^{*}}$ Paulo Renato dos Santos Costa $^{\mathrm{I}}$ \\ José Ivo Ribeiro Júnior ${ }^{\mathrm{II}}$ Leandro Maia"II Gabriel Augusto Monteiro ${ }^{\mathrm{II}}$
}

\section{RESUMO}

Os objetivos deste trabalho foram averiguar se a monofenilbutazona causa efeitos colaterais no trato digestório e lesões renais em pôneis hígidos e verificar a capacidade do omeprazol em inibir a gênese de úlceras gástricas. O experimento foi executado em duas etapas. Na primeira foram utilizados seis pôneis, sendo três deles tratados diariamente por via intravenosa (IV) com as doses de 3, 4,5 ou $6 \mathrm{mg} \mathrm{kg}^{-1}$ de monofenilbutazona durante 12 dias. Os demais, além de antiinflamatório, também receberam $3 \mathrm{mg} \mathrm{kg}^{-1}$ de omeprazol. Já na segunda etapa foram incluídos quatro pôneis hígidos, sendo dois tratados com doses diárias de $4,5 \mathrm{mg} \mathrm{kg}^{-1}$ de monofenilbutazona durante 12 dias e os demais com $5 \mathrm{~mL}$ de $\mathrm{NaCl}$ a $0,9 \%$, por via IV. Todos os pôneis foram submetidos à gastroscopia antes e após cada etapa experimental. Adicionalmente, na primeira etapa, foram realizadas urinálise e determinação dos valores de variáveis hematológicas (hematócrito e proteína plasmática total) e bioquímicas (creatinina, albumina, $\mathrm{Ca}^{+2}$ e $\mathrm{P}^{+3}$ ). Na primeira etapa, apenas os dois pôneis tratados com $6 \mathrm{mg} \mathrm{kg}^{-1}$ de monofenilbutazona apresentaram úlceras na região aglandular, ao longo da margo plicatus. Na segunda etapa, dois animais também apresentaram úlceras gástricas, sendo que um deles havia recebido apenas $\mathrm{NaCl}$ a $0,9 \%$. A ocorrência das úlceras não foi influenciada $(P>0,05)$ pela administração e pela dose da monofenilbutazona, nem pela presença do omeprazol. O efeito da monofenilbutazona sobre as variáveis hematológicas $e$ bioquímicas foi inexpressivo $\left(P^{+3}\right)$ ou ausente (hematócrito, proteína plasmática total, creatinina, albumina, $\mathrm{Ca}^{+2}$ ) $(P>0,05)$. Os resultados obtidos permitem concluir que: a ocorrência de úlceras na região aglandular de pôneis hígidos não sofre a influência da aplicação e da dose de monofenilbutazona, quando administrada durante 12 dias; úlceras em grau 4 na região aglandular de pôneis não necessariamente estão acompanhadas de sintomatologia clínica; pôneis hígidos toleram a aplicação de até $6 \mathrm{mg} \mathrm{kg}^{-1}$ de monofenilbutazona durante 12 dias sem o aparecimento de lesão renal; o efeito da administração de monofenilbutazona sobre as variáveis hematológicas e bioquímicas é de baixa intensidade ou ausente e não está confirmada a relação entre omeprazol e úlceras gástricas em pôneis tratados com monofenilbutazona.

Palavras-chave: antiinflamatórios, úlceras gástricas, lesão renal, inibidores da secreção ácida.

\section{ABSTRACT}

This research aimed to investigate whether mofebutazone causes gastrointestinal and renal side effects in healthy ponies as well as to verify the capacity of omeprazole to inhibit the genesis of gastric ulcers. The experiment was carried out in two phases. In the first, six ponies were used, with three of them being treated daily with different doses (3, 4.5 and $6 \mathrm{mg}$ $\mathrm{kg}^{-1}$ ) of intravenous (IV) mofebutazone for 12 days. The other ponies were given $3 \mathrm{mg} \mathrm{kg} \mathrm{of}^{-1}$ omeprazole in addition to the anti-inflammatory drug. In the second phase, four ponies were included, with two of them being treated daily with $4.5 \mathrm{mg} \mathrm{kg}^{-1}$ of mofebutazone for 12 days and the two remainders with $5 \mathrm{~mL}$ of $\mathrm{IV} \mathrm{NaCl}$ at $0.9 \%$. All ponies underwent gastroscopy before and after each experimental phase. Additionally, in the first phase, urine, hematological (hematocrit, and total plasma protein) and biochemical (creatinine, albumin, $\mathrm{Ca}^{+2}$ and $\mathrm{P}^{+3}$ ) analysis were determined. In the first phase, only the two ponies treated with $6 \mathrm{mg} \mathrm{kg}^{-1}$ of mofebutazone presented ulcers in the aglandular region along the margo plicatus. In the second phase, two animals also presented gastric ulcers, with one having received only $\mathrm{NaCl}$ at $0.9 \%$ solution. Ulcers occurrence was neither influenced $(P>0.05)$ by the administration and dose of mofebutazone, nor by the presence of omeprazole. Mofebutazone effect on the hematological and biochemical

'Departamento de Veterinária, Setor de Clínica, Universidade Federal de Viçosa (UFV), Campus Universitário, s/n, 36570-000,

Viçosa, MG, Brasil. E-mail:msouza@ufv.br. *Autor para correspondência.

IIDepartamento de Informática, UFV, Viçosa, MG, Brasil.

IIIUFV, Viçosa, MG, Brasil. 
variables was unremarkable $\left(P^{+3}\right)$ or absent (hematocrit, total plasma protein, creatinine, albumin, $\left.\mathrm{Ca}^{+2}\right)(P>0.05)$. Based on these results the following conclusions could be drawn: the occurrence of gastric ulcers in the aglandular region of healthy ponies was not influenced by application and dose of mofebutazone when administered for 12 days; grade four ulcers in the aglandular region of ponies may not be accompanied by clinical signs; healthy ponies tolerate application of up to $6 \mathrm{mg} \mathrm{kg}^{-1}$ of IV mofebutazone for 12 days without the occurrence of renal damage; hematological and biochemical variables are not or minimally influenced by mofebutazone and a relation between omeprazole and gastric ulcers could not be confirmed in mofebutazone-treated ponies.

Key words: anti-inflammatory drugs, gastric ulcers, renal lesion, gastric acid inhibitors.

\section{INTRODUÇÃO}

Os antiinflamatórios não-esteroidais (AINEs) são largamente usados na clínica de eqüinos por suas propriedades analgésicas, antiinflamatórias e adjuvantes no tratamento da endotoxemia (MATHEWS, 2002). Entre eles, a fenilbutazona, pertencente ao grupo das pirazolonas e derivada do ácido enólico, é uma das mais freqüentemente utilizadas, particularmente para as afecções do sistema músculo-esquelético, devido a sua eficácia e ao baixo custo (MacALLISTER et al., 1993), sendo a dose 2,0 a 4,4mg kg-1 a cada 12 ou 24 horas, recomendada por via intravenosa (IV) ou oral (ROBINSON, 2003).

Como a fenilbutazona atua inibindo não seletivamente a isoforma COX-1 em detrimento da COX2 , os efeitos colaterais mais freqüentemente observados são aqueles relacionados aos órgãos e sistemas onde a COX-1 é encontrada, sendo eles: hiporexia, gastrite difusa, erosões ou ulcerações gástricas, amolecimento das fezes, gastroenterite hemorrágica, trombose venosa, nefrite, falha renal aguda e lesão renal crônica (SNOW et al., 1981). Além disso, também pode ocorrer diminuição dos níveis de cálcio e da proteína plasmática total (PPT) (SNOW et al., 1979) em eqüinos tratados com altas doses ou por tempo prolongado.

As lesões na mucosa do trato digestório de eqüinos são decorrentes do efeito antiprostaglandina (PGE e PGE $_{2}$ ) da fenilbutazona (MacALLISTER, 1983). As prostaglandinas aumentam o fluxo sangüíneo microcirculatório da mucosa gástrica e a produção de muco, além de reduzirem a produção de ácido gástrico. Portanto, a inibição da síntese de prostaglandinas pode criar condições propícias para ulceração no trato digestório (ANDREWS \& NADEAU, 1999; MURRAY, 1999), que resultam de um desequilíbrio entre fatores agressores ( $\mathrm{HCl}$, pepsina) e protetores da mucosa (barreira de muco-bicarbonato, $\mathrm{PGE}_{2}$, fluxo sangüíneo)
(ANDREWS \& NADEAU, 1999). O omeprazol, utilizado na dose de 1,5 a 4,0 $\mathrm{mg} \mathrm{kg}^{-1}$ por via oral a cada 24 horas, é considerado um dos mais efetivos inibidores da secreção gástrica, atuando pela inibição da bomba de prótons $\mathrm{H}^{+}, \mathrm{K}^{+}$-ATPase (DAURIO et al., 1999), sendo a dose oral diária de $4 \mathrm{mg} \mathrm{kg}^{-1}$ durante 28 dias a que demonstra maior porcentagem de eficácia (MacALLISTER, 1999).

A monofenilbutazona, uma pirazolona derivada da fenilbutazona, produzida pelo laboratório Vetnil, foi liberada pelo Ministério da Agricultura para utilização em animais domésticos em 30 de janeiro de 2003, tendo demonstrado, segundo o fabricante, efeitos benéficos nos eqüídeos na dose diária de $6 \mathrm{mg} \mathrm{kg}^{-1}$, por via IV lenta, durante cinco dias consecutivos. Apesar de já estar no mercado brasileiro há cinco anos, não existem relatos científicos disponíveis que comprovem sua eficácia terapêutica ou sua toxidez no trato digestório e no sistema urinário de eqüinos.

Em humanos, entre os efeitos colaterais ocasionados pela monofenilbutazona, destacam-se discreto aumento na concentração da hemoglobina, redução na taxa de sedimentação dos eritrócitos, além de redução nos níveis séricos de ferro e albuminúria, sendo considerados menos expressivos quando comparados com os da fenilbutazona (THUNE, 1967). Até o momento, apenas dois trabalhos avaliaram a toxicidade da monofenilbutazona no trato digestório de cães. COSTA et al. (2005) administraram monofenilbutazona por via IV na dose diária de 30mg $\mathrm{kg}^{-1}$ para quatro cães, durante 21 dias. Nenhum dos animais desenvolveu erosões e/ou úlceras gástricas. Já COSTA et al. (2007), utilizaram a mesma dose durante o mesmo período em oito cães, sendo observadas lesões de baixa gravidade, caracterizadas pela presença de hemorragias puntiformes e erosivas focais. Nesse sentido, os objetivos deste trabalho foram averiguar se a monofenilbutazona causa efeitos colaterais no trato digestório e lesões renais em pôneis e verificar a capacidade do omeprazol em inibir a gênese de úlceras gástricas.

\section{MATERIAL E MÉTODOS}

O experimento foi realizado em duas etapas, com duração de 12 dias cada, com intervalo de três meses entre elas. Para isso, seis pôneis mestiços (três machos e três fêmeas), com idade entre um e quadro anos $(2 \pm 1,09)$ e peso corporal entre 54 e $127 \mathrm{~kg}$ $(88,50 \pm 25,36)$, foram selecionados a partir de um plantel de 14 animais criados no município de Araponga (MG) mediante minucioso exame físico, urinálise e gastroscopia, a fim de descartar úlceras espontâneas. 
Os animais foram numerados de I a VI e mantidos durante todo o período experimental em piquete de Brachiaria decumbens com área de $3000 \mathrm{~m}^{2}$, com fornecimento de capim elefante (Pennisetum purpureum) e entre 700 e $1000 \mathrm{~g}$ de ração granulada por animal/dia (15\% proteína) no cocho. Sal mineral e água foram deixados ad libitum. Ainda que os pôneis tenham sido obtidos da microrregião onde foi realizado o experimento, foi destinado um período de três semanas para adaptação ao ambiente hospitalar. Nesse período, os animais foram vermifugados com moxidectina e submetidos a exame físico diário (entre 8 e 10h), sendo exatamente o mesmo utilizado durante ambas as etapas experimentais.

Na primeira etapa, foram investigados os efeitos colaterais das doses de monofenilbutazona (Monofenew $^{\circledR}$, Laboratório Vetnil) no trato digestório e no sistema renal dos pôneis. Também foi testada a capacidade do omeprazol (Equiprazol ${ }^{\circledR}$, Laboratório Vetnil) em prevenir a formação de úlceras gástricas.

Antes de iniciar esta etapa, os pôneis foram submetidos a uma nova gastroscopia. Para isso, os animais foram submetidos a jejum alimentar e hídrico de 14 horas. Para a anestesia, foi utilizada xilazina a $2 \%$, seguida de solução a 10\% de éter gliceril guaicol (EGG) diluído em Ringer com lactado de sódio, administrado em infusão contínua rápida até a obtenção do decúbito lateral esquerdo. A partir desse momento, a infusão passou a ser lenta. Após a indução anestésica, o videoendoscópio foi introduzido por via oral e o esôfago distendido com ar, sendo o tubo direcionado até sua chegada ao cárdia. O estômago foi examinado na seguinte seqüência: região aglandular, margo plicatus, região glandular e piloro. A caracterização das lesões observadas por gastroscopia foi baseada na classificação descrita por MURRAY et al. (1987), em uma escala de 0 a 4, sendo: 0: quando a mucosa encontrava-se sem alteração; 1: quando uma a duas lesões foram observadas; 2: quando foram observadas três a cinco lesões de forma localizada ou uma única lesão difusa; 3: na presença de uma a cinco lesões de forma localizada e com visível quadro de hemorragia ou múltiplas lesões difusas, que aparentassem média a moderada perda de superfície epitelial e 4: quando mais de cinco lesões localizadas foram observadas ou quando estas eram múltiplas e difusas e com extensiva perda da superfície epitelial e/ou com hemorragia.

Uma vez realizada a gastroscopia, os animais foram sorteados. Os pôneis de número IV, V e VI receberam, respectivamente, as doses de 3, 4,5 e 6mg $\mathrm{kg}^{-1} \mathrm{dia}^{-1}$ de monofenilbutazona por via IV, durante 12 dias, assim como $3 \mathrm{mg} \mathrm{kg}^{-1} \mathrm{dia}^{-1}$ de omeprazol por via oral. Os demais pôneis (I, II e III) receberam, respectivamente, as doses de 3, 4,5 ou $6 \mathrm{mg} \mathrm{kg}^{-1}$ de monofenilbutazona sem, entretanto, receber omeprazol. Os animais foram submetidos a exame físico diário durante um período de doze dias. O exame consistiu na avaliação das seguintes variáveis clínicas: postura, comportamento, apetite, consistência das fezes, coloração das mucosas, grau de hidratação, tempo de enchimento capilar (TEC), freqüência cardíaca (FC), freqüência respiratória (FR) e temperatura corporal.

Amostras de sangue foram coletadas no dia zero, ou seja, imediatamente antes da administração da monofenilbutazona, assim como no sétimo dia do fornecimento do medicamento e dois dias (14º dia) após o término do experimento, para determinação da concentração do hematócrito, PPT, albumina, creatinina, cálcio iônico $\left(\mathrm{Ca}^{+2}\right)$ e fósforo $\left(\mathrm{P}^{+3}\right)$. Para isso, após a anti-sepsia com álcool iodado, foram obtidas amostras de $5 \mathrm{~mL}$ de sangue por punção da veia jugular, em tubos de vidros a vácuo contendo o anticoagulante EDTA. O sangue total foi utilizado para a determinação do hematócrito. O plasma obtido a partir da centrifugação das amostras de sangue (1752g, durante 10 minutos) foi utilizado para mensuração das PPT. Para a determinação da albumina, creatinina, $\mathrm{Ca}^{+2} \mathrm{e} \mathrm{P}^{+3}$, foram obtidas amostras de $10 \mathrm{~mL}$ de sangue em tubos siliconizados a vácuo sem anticoagulante. Após sedimentação, o soro foi obtido por centrifugação (1752g durante 10 minutos).

A concentração do hematócrito (\%) no sangue foi realizada em aparelho semi-automático. A refratometria foi a técnica utilizada para a análise da concentração das PPT. A determinação da concentração da creatinina foi realizada por espectrofotometria, utilizando-se o método de Jaffé modificado. A concentração do $\mathrm{Ca}^{+2}$ foi determinada por eletrodos seletivos, já as concentrações do íon fósforo e da albumina foram determinadas por reação enzimática colorimétrica.

Antes e após o término do experimento (14ํㅜㅇ dia), foram obtidas amostras de urina por sonda uretral para urinálise, sendo realizado exame físico, químico e do sedimento. Adicionalmente, dois dias após o término da administração da monofenilbutazona associada ou não ao omeprazol, os pôneis foram submetidos a uma nova gastroscopia.

A segunda etapa foi realizada após avaliação dos resultados obtidos na primeira a fim de averiguar apenas a formação de úlceras gástricas em animais recebendo ou não a dose intermediária utilizada na primeira etapa, ou seja, de $4,5 \mathrm{mg} \mathrm{kg}^{-1}$ de monofenilbutazona. Para essa etapa, novamente os pôneis foram previamente submetidos à gastroscopia, 
sendo utilizados apenas quatro animais (numerados de I a IV) não portadores de úlceras gástricas no momento do exame. Após sorteio, os pôneis II e III foram tratados com doses diárias de $4,5 \mathrm{mg} \mathrm{kg}^{-1}$ de monofenilbutazona durante 12 dias e os demais (I e IV) com $5 \mathrm{~mL}$ de $\mathrm{NaCl}$ a $0,9 \%$, por via IV. Após o término do tratamento, os animais foram novamente submetidos à gastroscopia.

A análise estatística foi processada no SAEG 9.0 a 5\% de significância para os resultados da primeira fase. Para a segunda fase, foram feitas apenas descrições dos resultados encontrados. Foi verificada a relação de dependência das características avaliadas em função da dosagem da monofenilbutazona, do tempo de tratamento e do protetor omeprazol. Para as variáveis hematológicas (hematócrito e PPT) e bioquímicas (creatinina, $\mathrm{Ca}^{+2} \mathrm{e}^{+3}$ ), foi realizada análise de regressão em função do protetor ( 0 = ausência e 1 = presença), das dosagens de monofenilbutazona (3; 4,5 e $6 \mathrm{mg} \mathrm{kg}^{-1}$ ) e do tempo de tratamento, com período máximo de 12 dias, sendo os coeficientes testados pelo teste t-Student. Para os resultados da gastroscopia (0 = ausência de úlcera e 1 = presença de úlcera) no dia 0 e aos 14 dias, foi realizada uma análise de regressão logística binária por meio do modelo logit.

\section{RESULTADOS E DISCUSSÃO}

Durante o exame físico diário não foram observadas alterações na postura, no comportamento, no apetite, no grau de hidratação e na consistência das fezes nos animais de ambos os grupos e em ambas as etapas. As mucosas se mantiveram normocoradas e o TEC foi inferior a dois segundos. Todos os pôneis ganharam peso durante o experimento, o que provavelmente se deve à melhoria no manejo alimentar

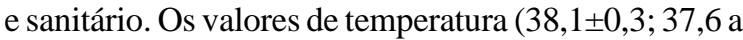
$38,5^{\circ} \mathrm{C}$ ) se mantiveram dentro dos considerados como de referência para a espécie. Já os valores médios e máximos de FC (56,2×9,5; 45 a 78bpm) e FR (26,2+10,9; 12 a 48 respirações por minuto) estiveram acima dos de referência, que são de $40 \mathrm{bpm}$ para a FC e de 20 respirações por minuto para FR (SPEIRS, 1999). Apesar desses valores elevados, não foram detectadas alterações cardíacas e pulmonares na auscultação. Este aumento pode estar relacionado com o estresse decorrente do exame físico.

Apesar de se mostrarem aparentemente sadios, a gastroscopia realizada na primeira etapa, após 12 dias de aplicação diária das três doses (3; 4,5 e 6mg $\mathrm{kg}^{-1}$ ) de monofenilbutazona, revelou três úlceras na mucosa gástrica do pônei III (grau 2, Figura 1 a, b) e uma úlcera no pônei VI (grau 1), na região aglandular, ao longo da margo plicatus. Erosões foram observadas na mesma região nos pôneis II e IV. Os animais I e V não apresentaram alterações na mucosa gástrica.

Apesar das úlceras gástricas, como mencionado anteriormente, os animais permaneceram assintomáticos, não sendo observados sinais de bruxismo, sialorréia, inapetência, diarréia, tendência a permanecer em decúbito dorsal, cólica ou qualquer outro indício de comprometimento do trato digestório. Estes resultados corroboram os resultados de MacALLISTER \& SANGIAH (1993), que não observaram sinais clínicos associados às úlceras gástricas resultante do tratamento com flunixina meglumina na dose terapêutica de $1,1 \mathrm{mg} \mathrm{kg}^{-1}$. A maioria dos trabalhos relaciona esses efeitos colaterais ao uso de doses elevadas (10, 15 ou 30 $\mathrm{mg} \mathrm{kg}^{-1}$ ) ou prolongadas (14 dias) de fenilbutazona (SNOW et al., 1979; MacKAY et al., 1983). No presente trabalho, foi extrapolado o período de aplicação recomendado pelo fabricante Vetnil para a monofenilbutazona, que é de apenas cinco dias.

A ocorrência das úlceras não esteve relacionada $(\mathrm{P}>0,05)$ com a dose da monofenilbutazona administrada, nem com a presença do omeprazol. Entretanto, devido ao número de animais afetados, não foi possível averiguar se a quantidade e a severidade das úlceras presentes no pônei III foram decorrentes da ausência de proteção pelo omeprazol. É provável que o estresse decorrente da mudança de ambiente, da manipulação diária e, finalmente, da própria aplicação dos fármacos, conforme mencionado pela literatura (MacALLISTER et al., 1992; MURRAY, 1999), possa ter contribuído para a quantidade e a severidade das úlceras encontradas no animal III. Também é importante destacar a possibilidade da ocorrência de uma resistência individual dos pôneis com relação à gênese da úlcera. Segundo COSTA et al. (2007), a fisiopatologia das lesões por estresse pode estar associada à redução do fluxo sangüíneo na mucosa por vasoconstrição esplâncnica e pelos níveis elevados de catecolaminas circulantes. Adicionalmente, o aumento na concentração de corticosteróides endógenos decorrente do estresse pode inibir a síntese de prostaglandinas. Sabe-se que o decréscimo dessas substâncias acarreta um desequilíbrio nos fatores de proteção da mucosa, sendo considerado como a causa primária das úlceras presentes em potros e eqüinos adultos (ANDREWS \& NADEAU, 1999).

A manifestação das úlceras apenas nos dois pôneis que receberam a dose de $6 \mathrm{mg} \mathrm{kg}^{-1}$ pode ter sido potencializada pelos fatores já mencionados como relacionados ao estresse. Esta hipótese é reforçada pelos resultados obtidos na segunda etapa, quando 

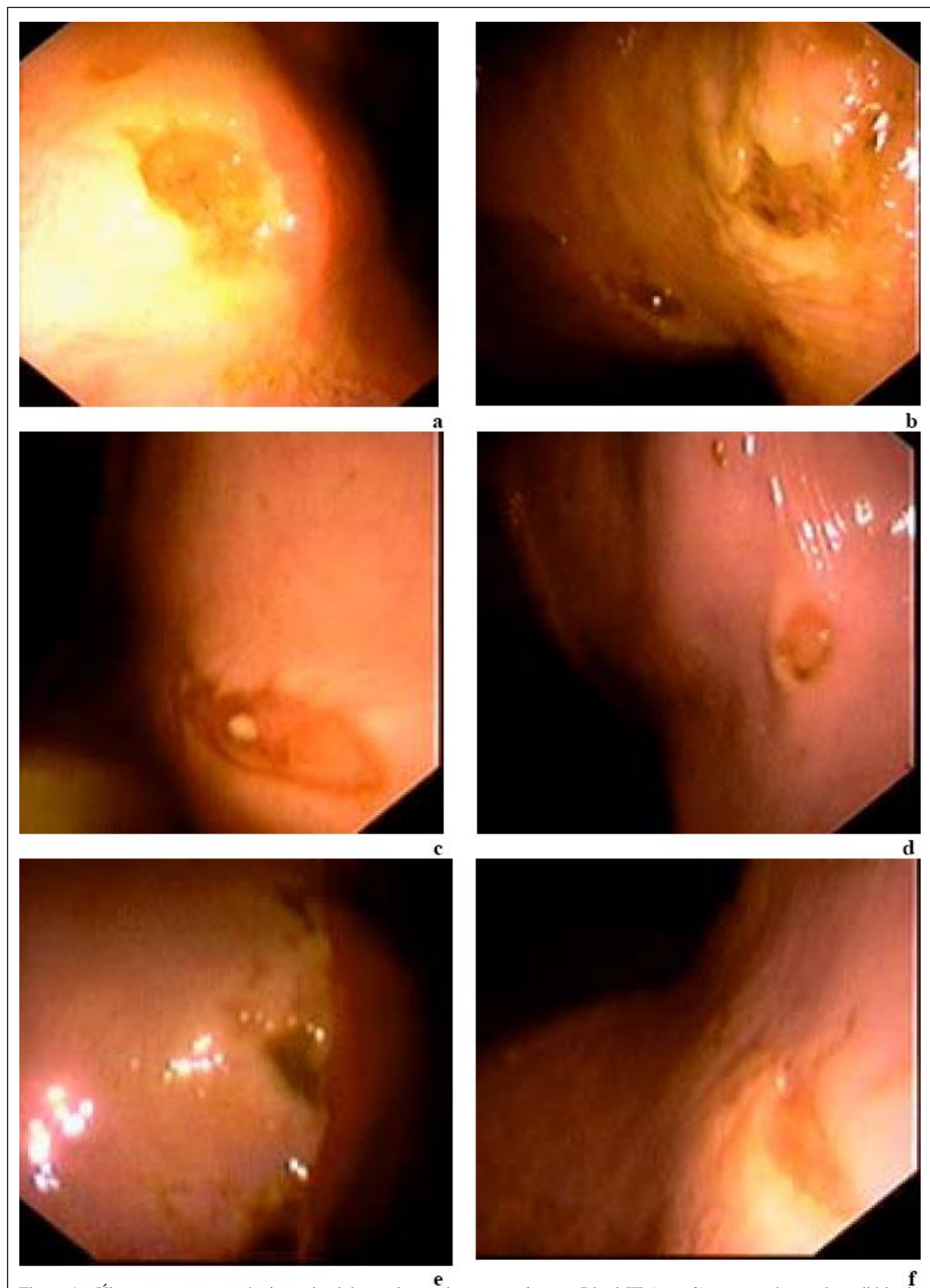

Figura 1 - Úlceras na mucosa gástrica aglandular ao longo do margo plicatus. Pônei III (grau 2), que recebeu a dose diária de $6 \mathrm{mg} \mathrm{kg}^{-1}$ de monofenilbutazona (primeira etapa) (a e b). Pônei de I (grau 1), que recebeu $\mathrm{NaCl}$ a 0,9\% (segunda etapa) (c e d). Pônei III (grau 4), que recebeu a dose diária de $4,5 \mathrm{mg} \mathrm{kg}^{-1}$ de monofenilbutazona na segunda etapa (e e f). 
tanto um animal que recebeu monofenilbutazona como outro que recebeu $\mathrm{NaCl}$ 0,9\% apresentaram úlceras. Portanto, a gastroscopia dos quatro animais incluídos na segunda etapa revelou a presença de duas úlceras na mucosa gástrica aglandular, ao longo da margo plicatus (grau 1, Figura 1 c,d) no pônei I (que recebeu $\mathrm{NaCl}$ 0,9\%) e sete úlceras (grau 4, Figura 1 e,f) no pônei III. Dessas sete úlceras, havia duas de maior diâmetro, entretanto, nenhuma delas se mostrou hemorrágica. Provavelmente, o aparecimento das úlceras não foi manifestado nem pela monofenilbutazona, nem pelo tempo de administração da droga.

VATISTAS et al. (1999), estudando o estresse em eqüinos, sugeriram diversas condições como possíveis de aumentar a concentração sérica de cortisol. Por outro lado, na opinião dos autores, a dieta não altera os níveis dessa variável. É possível que no pônei I o incômodo relacionado à aplicação de IV diária do $\mathrm{NaCl}$ a $0,9 \%$ tenha gerado condições estressantes suficientes para formação das úlceras. Esta relação estresse versus aplicação de medicamentos foi sugerida por MacALLISTER et al. (1992) em pôneis, após administrar por via intramuscular flunixina meglumina na dose de $1,5 \mathrm{mg} \mathrm{kg}^{-1}$, a cada 8 horas, durante seis dias. No pônei III, o estresse também pode ter sido um importante fator predisponente na gênese das úlceras gástricas. Os resultados do presente estudo se assemelham aos resultados de MacALLISTER et al. (1993), que compararam a ocorrência de úlceras após administração de flunixina meglumina e de $\mathrm{NaCl}$ a $0,9 \%$ para eqüinos, não sendo encontrada diferença estatística entre os dois grupos.

A maioria das variáveis hematológicas e bioquímicas avaliadas nos três dias de coleta (dia zero, sete dias após o início e dois dias após o término do tratamento) se manteve entre os valores considerados como de referência para a espécie eqüina. À exceção do cálcio iônico e do fósforo, as demais variáveis não foram influenciadas $(\mathrm{P}>0,05)$ por nenhum dos três fatores (omeprazol, dose e tempo de tratamento).

Os valores médios e o desvio padrão do hematócrito foram de $29 \pm 2 \%$, portanto, dentro da normalidade. A redução nos valores de PPT é um achado freqüente em eqüinos intoxicados com fenilbutazona (SNOW et al., 1979, 1981; MacALLISTER, 1983; MONREAL et al., 2004). Este resultado foi observado em pôneis submetidos a doses diárias de 10 a $12 \mathrm{mg} \mathrm{kg}^{-1}$ por via oral durante seis a oito dias (SNOW et al., 1981), sendo resultante da perda de proteína pelo trato digestório, inclusive na ausência de ulcerações gástricas. Também há relatos de hipoproteinemia após administração da dose terapêutica (4,4mg $\left.\mathrm{kg}^{-1}\right)$ de fenilbutazona durante treze dias (MacALLISTER et al., 1993). Entretanto, o intervalo de aplicação foi de apenas oito horas, sendo menor que o recomendado pela literatura. No presente experimento, a dose de monofenilbutazona utilizada não alterou $(\mathrm{P}>0,05)$ a concentração plasmática das proteínas $\left(7,2 \pm 0,4 \mathrm{~g} \mathrm{dL}^{-1}\right)$, corroborando os resultados de LEME (2000), que também não encontrou redução nos valores dessa variável após administração de fenilbutazona por via intramuscular em 25 bovinos na dose de 5 ou $10 \mathrm{mg} \mathrm{kg}^{-1}$, durante cinco ou 10 dias. Os valores de albumina $\left(2,3 \pm 0,23 \mathrm{~g} \mathrm{dL}^{-1}\right)$ também não sofreram alterações, diferentemente dos resultados obtidos por MacKAY et al. (1983), que relataram redução progressiva dessa variável sérica em eqüinos intoxicados com fenilbutazona na dose de 15 a 30mg $\mathrm{kg}^{-1}$, por via oral e IV, durante duas semanas. Por outro lado, SNOW et al. (1979), estudando pôneis intoxicados com $10 \mathrm{mg} \mathrm{kg}^{-1}$ de fenilbutazona, não observaram alteração da proporção albumina: globulina.

A urinálise e os níveis de creatinina $\left(1,35 \pm 0,15 \mathrm{mg} \mathrm{dL}^{-1}\right)$ se mostraram dentro da normalidade (1,2 a 1,9mg dL $\mathrm{m}^{-1}$, KANEKO et al., 1997) em todos os pôneis. Em eqüinos, apesar de os sinais clínicos associados à doença renal decorrentes da utilização de AINEs serem inespecíficos, a poliúria, a polidipsia, a perda de peso e a depressão são considerados achados relevantes. A ausência de alterações nos exames acima mencionados nos pôneis do presente estudo pode sugerir uma ação mais seletiva da monofenilbutazona em COX-2, evitando a inibição das prostaglandinas em nível renal, com preservação do fluxo sangüíneo, da ação vasodilatadora $\left(\mathrm{PGE}_{2}\right)$ e, conseqüentemente, da manutenção da integridade dos néfrons. Esses resultados se assemelham aos resultados de MacALLISTER et al. (1993), que não encontraram modificações no exame de urina de eqüinos tratados com outros AINEs. Nesse sentido, com base nos níveis de creatinina que se mantiveram dentro dos valores de referência e no exame físico diário realizado ao longo dos 12 dias de avaliação, assim como nos resultados da urinálise, não existem indícios de lesão renal ocasionada pela monofenilbutazona nos pôneis estudados.

SNOW et al. (1979) encontraram decréscimo na concentração de cálcio em quatro pôneis (40\%, $\mathrm{N}=10$ ) tratados diariamente com fenilbutazona (10 a $12 \mathrm{mg} \mathrm{kg}^{-1}$ ) por via oral durante seis a oito dias. SNOW et al.(1981) e MacALLISTER(1983) também observaram redução nos valores desse íon em pôneis e eqüinos, respectivamente, intoxicados com fenilbutazona. Os autores atribuíram este decréscimo à queda protéica, já que $50 \%$ do cálcio plasmático estão ligados às proteínas. No presente estudo, os valores médios de 
$\mathrm{Ca}^{+2}\left(5,83 \pm 0,34 \mathrm{mg} \mathrm{dL}^{-1}\right)$, nos animais que receberam omeprazol, foi maior $(\mathrm{P}<0,05)$ em relação àqueles que não receberam. Este resultado gera uma pequena dúvida, ou seja, a de que a presença do omeprazol aumentou a concentração, ou a de que a ausência do omeprazol diminuiu essa concentração. Nesse último caso, conclui-se que o omeprazol pode não aumentar os níveis de cálcio, mas os mantêm.

Os níveis séricos de fósforo $(5,23 \pm 1,09 \mathrm{mEq}$ $\left.\mathrm{L}^{-1}\right)$ aumentaram $(\mathrm{P}<0,05)$ em função do tempo de tratamento com monofenilbutazona e diminuíram $(\mathrm{P}<0,05)$ em função da utilização do omeprazol. Como a excreção urinária de fósforo depende da filtração glomerular e da reabsorção tubular, geralmente a redução do fluxo sangüíneo renal e da taxa de filtração glomerular resulta em hiperfosfatemia. Aumento nos valores de $\mathrm{P}^{+3}$ plasmáticos foi observado por SNOW et al. (1979) e MacKAY et al. (1983) em alguns pôneis e eqüinos, respectivamente, recebendo doses elevadas de fenilbutazona por um período de duas semanas. Por outro lado, quatro animais apresentaram redução nos níveis dessa variável nos $10^{\circ}$ e $18^{\circ}$ dias após tratamento com fenilbutazona (SNOW et al., 1979). De fato, há controvérsias com relação aos valores séricos de fósforo em animais que recebem AINEs, inclusive pôneis. Alguns trabalhos mostram aumento e outros mostram diminuição (SNOW et al., 1979; MacKAY et al., 1983).

Estudos sobre a relação entre AINEs e úlceras gástricas em eqüinos são complexos, já que vários fatores podem resultar na formação de lesões gástricas, tais como: condição fisiológica do estômago da espécie (pH freqüentemente inferior a 2 - MURRAY, 1999), jejum prolongado (pH pode alcançar valores tão baixos quanto 1,55 - MURRAY \& SCHUSSER, 1993), exercícios intensos em animais de esporte (aumento na pressão abdominal, redução no volume estomacal e refluxo de ácidos para a região aglandular - VATISTAS et al., 1999), enfermidades (animais inapetentes ou anoréxicos - MURRAY, 1999), assim como as condições estressantes anteriormente mencionadas, que podem ocasionar níveis elevados de corticosteróides circulantes, os quais inibem a síntese de prostaglandinas e de outros mediadores químicos, criando um ambiente gástrico favorável à ulceração (ANDREWS \& NADEAU, 1999).

Não há dúvida em relação à importância de uma análise cautelosa dos resultados em razão do número amostral reduzido. Obviamente que limitações podem ser associadas ao pequeno número de animais avaliados, mas devido a dificuldades técnicas envolvidas na amostragem de um maior número de indivíduos, no presente estudo, prevaleceu o princípio da razoabilidade, também adotado em outros estudos que envolveram grandes animais. Além disso, é preciso registrar que os achados aqui relatados merecem a devida contextualização e ponderação para sua extrapolação em maiores populações. Ainda que no presente estudo tentou-se padronizar o manejo adotado, algumas das condições acima mencionadas e o próprio temperamento individual dos animais podem não ter permitido um controle e a mensuração exata. No entanto, todas as medidas possíveis foram tomadas, tentando manter um controle local das condições experimentais.

\section{CONCLUSÕES}

A partir desse estudo, conclui-se que o aparecimento de úlcera gástrica na região aglandular de pôneis hígidos não sofre a influência da aplicação e da dose de monofenilbutazona, quando administrada durante 12 dias; úlceras em grau 4 na região aglandular de pôneis não necessariamente são acompanhadas de sintomatologia clínica; pôneis hígidos toleram a aplicação diária de até $6 \mathrm{mg} \mathrm{kg}^{-1}$ de monofenilbutazona durante 12 dias sem o aparecimento de lesão renal; o efeito da administração diária de monofenilbutazona sobre variáveis hematológicas (hematócrito, proteínas plasmáticas totais) e bioquímicas (creatinina, albumina, $\mathrm{Ca}^{+2}$ e $\mathrm{P}^{+3}$ ) de pôneis hígidos é de baixa intensidade $\left(\mathrm{P}^{+3}\right)$ ou ausente; não está comprovada a relação do omeprazol com a ausência ou a presença de úlceras em pôneis tratados com monofenilbutazona.

\section{COMITÊ DE ÉTICA E BIOSSEGURANÇA}

Este trabalho foi aprovado pela Comissão de Ética do Departamento de Veterinária (processo nํㅜ 07/2006), da Universidade Federal de Viçosa, sendo que os estudos foram realizados de acordo com as normas do Código de Ética Profissional do Médico Veterinário e do Colégio Brasileiro de Experimentação Animal (COBEA).

\section{REFERÊNCIAS}

ANDREWS, F.M.; NADEAU, J.A. Clinical syndromes of gastric ulceration in foals and mature horses. Equine Veterinary Journal, Newmarket, Suppl.29, p.30-33, 1999.

COSTA, P.R.S. et al. Avaliação endoscópica da mucosa gastroduodenal em cães tratados com monofenilbutazona. Revista da Universidade Rural Série Ciência da Vida, Seropédica, v.25, p.159-160, 2005.

COSTA, P.R.S. et al. Endoscopia gastroduodenal após administração de nimesulida, monofenilbutazona e meloxicam em cães. Arquivo Brasileiro de Medicina Veterinária e Zootecnia, Belo Horizonte, v.59, n.4, p.903-909, 2007. 
DAURIO, C.P. et al. Effect of omeprazole paste on gastric acid secretion in horses. Equine Veterinary Journal, Newmarket, Suppl.29, p.59-62, 1999.

KANEKO, J.J. et al. Clinical biochemistry of domestic animals. 5.ed. San Diego : Academic, 1997. 932p.

LEME, F.O.P. Estudo clínico, laboratorial e post-mortem de bovinos medicados com fenilbutazona por via intramuscular. 2000. 74f. Dissertação (Mestrado em Clínica e Cirurgia Veterinárias) - Curso de Pós-graduação em Medicina Veterinária, Universidade Federal de Minas Gerais.

MacALLISTER, C.G. Effects of toxic doses of phenylbutazone in ponies. American Journal of Veterinary Research, Washington, v.44, n.12, p.2277-2279, 1983.

MacALLISTER, C.G. A review of medical treatment for peptic ulcer disease. Equine Veterinary Journal, Newmarket, Suppl. 29, p.45-49, 1999.

MacALLISTER, C.G. et al. Effect of a histamine H2 type receptor antagonist (WY 45, 727) on the healing of gastric ulcers in ponies. Journal of Veterinary Internal Medicine, Oklahoma, v.6, n.5, p.271-275, 1992.

MacALLISTER, C.G. et al. Comparison of adverse effects of phenylbutazone, flunixin meglumine, and ketoprofen in horses. Journal of American of Veterinary Medical Association, Schaumburg, v.202, n.1, p.71-77, 1993.

MacALLISTER, C.G.; SANGIAH, S. Effect of ranitidine on healing of experimentally induced gastric ulcers in ponies. American Journal of Veterinary Research, Washington, v.54, n.7, p.1103-1107, 1993.

MacKAY, R.J. et al. Effects of large doses of phenylbutazone administration to horses. American Journal of Veterinary Research, Washington, v.44, n.5, p.774-780, 1983.

MATHEWS, K.A. Non-steroidal anti-inflammatory analgesics: a review of current practice. Journal of Veterinary Emergency and Critical Care, Boston, v.12, n.2, p.89-97, 2002.

MONREAL, L. et al. Lower gastric ulcerogenic effect of suxibuzone compared to phenylbutazone when administered orally to horses. Research of Veterinary Science, Saskatoon, v.2, n.76, p.145-149, 2004.

MURRAY, M.J. Pathophysiology of peptic disorders in foals and horses: a review. Equine Veterinary Journal, Newmarket, Suppl.29, p.14-18, 1999.

MURRAY, M.J.; SCHUSSER, G.F. Measurement of 24-h gastric $\mathrm{pH}$ using an indwelling $\mathrm{pH}$ electrode in horses unfed, fed and treated with ranitidine. Equine Veterinary Journal, Newmarket, v.25, n.5, p.417-421, 1993.

MURRAY, M.J. et al. Equine gastric ulcer syndrome: endoscopic survey of asymptomatic foals. In: ANNUAL CONVENTION OF THE AMERICAM ASSOCIATION EQUINE PRACTITIONERS, 33., 1987, New Orleans, Lousiana. Proceedings... New Orleans: AAEP, 1988. p.769-776.

ROBINSON, N. E. Current therapy in equine medicine. 5.ed. St. Louis : Saunders. Appendix 1, 2003. p.866.

SAEG - Sistema para análises estatísticas, versão 9.0. Capturado em 12 dez. 2007. Online. Disponível na Internet: http://www.ufv.br/saeg

SNOW, D.H. et al. Phenylbutazone toxicity in ponies. Veterinary Record, London, v.105, n.2, p.26-30, 1979.

SNOW, D.H. et al. Phenylbutazone toxicosis in equidae: a biochemical and pathophysiologic study. American Journal of Veterinary Research, Washington, v.42, n.10, p.17541759, 1981.

SPEIRS, V.C. Exame clínico de eqüinos. Porto Alegre: Artmed, 1999. 366p.

THUNE, S. Comparison of phenyl and monophenylbutazone (mobutazone), especially in respect to the incidence of side effects. Acta Rheumatological Scandinavica, Siena, v.13, n.1, p.63-80, 1967.

VATISTAS, N.J. et al. Induction and maintenance of gastric ulceration in horses in simulated race training. Equine Veterinary Journal, Newmarket, Suppl. 29, p.40-44, 1999. 